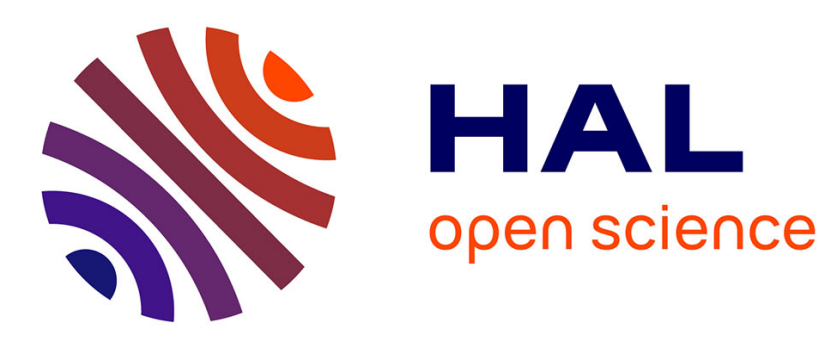

\title{
Photo-modulable Molecular Transport Junctions based on Organometallic Molecular Wires
}

Fanben Meng, Yves-Marie Hervault, Lucie Norel, Karine Costuas, Colin van

Dyck, Victor Geskin, Jérôme Cornil, Huey Hoon Hng, Stéphane Rigaut, Xiaodong Chen

\section{To cite this version:}

Fanben Meng, Yves-Marie Hervault, Lucie Norel, Karine Costuas, Colin van Dyck, et al.. Photomodulable Molecular Transport Junctions based on Organometallic Molecular Wires. Chemical Science, 2012, 3 (10), pp.3113-3118. 10.1039/C2SC20323E . hal-00753710

\section{HAL Id: hal-00753710 \\ https://hal.science/hal-00753710}

Submitted on 22 Oct 2013

HAL is a multi-disciplinary open access archive for the deposit and dissemination of scientific research documents, whether they are published or not. The documents may come from teaching and research institutions in France or abroad, or from public or private research centers.
L'archive ouverte pluridisciplinaire HAL, est destinée au dépôt et à la diffusion de documents scientifiques de niveau recherche, publiés ou non, émanant des établissements d'enseignement et de recherche français ou étrangers, des laboratoires publics ou privés. 


\title{
Photo-modulable Molecular Transport Junctions based on Organometallic Molecular Wires $\uparrow$
}

\author{
Fanben Meng, ${ }^{a}$ Yves-Marie Hervault, ${ }^{b}$ Lucie Norel, ${ }^{b}$ Karine Costuas, ${ }^{b}$ Colin Van Dyck, ${ }^{c}$ Victor Geskin, ${ }^{c}$ \\ Jérôme Cornil, ${ }^{c}$ Huey Hoon Hng, ${ }^{a}$ Stéphane Rigaut ${ }^{* b}$ and Xiaodong Chen ${ }^{* a}$ \\ 5
}

\author{
Received 15th March 2012, Accepted 5th August 2012 / DOI: 10.1039/c2sc20323e
}

Photo-modulable molecular transport junctions are developed via on-wire lithography-fabricated nanogap functionalized with a dithienylethene unit bearing two ruthenium fragments. A reversible and repeatable bi-state conductive switching upon alternate irradiation of UV and visible light can be distinctly observed. Theoretical calculations further suggest that bi-directional isomerization is 10 due to the ruthenium moieties that modulate judiciously the electronic coupling between the photochromic part and the metal electrodes, and that the differences in electronic structure between the two isomers (open and closed states) are responsible for conductivity switching.

\section{Introduction}

Molecular transport junctions (MTJs) are essential structures for developing molecule-based electronics. ${ }^{1}$ Building molecular function 15 into MTJs to exploit advanced nanodevices with promising applications is both a formidable challenge and an opportunity that, if realized, could have a revolutionary impact on molecular electronics. ${ }^{2}$ Several functional MTJs, such as diodes, ${ }^{3}$ transistors, ${ }^{4}$ switches, ${ }^{5}$ and memristors, ${ }^{6}$ have been made to show promising application in fields from information technology to nano-bio interface. Integrating photo-switchable molecules, ${ }^{7}$ such as dithienylethylene (DTE), stilbenes, and azobenzenes, into nanodevices is receiving increasing attention. ${ }^{8}$ For example, for DTE molecules in solution, ${ }^{9}$ the photo-switching is induced by structure cyclization from a cross-conjugated 20 open state to a $\pi$-conjugated closed state under ultraviolet (UV) light, while the reverse process is triggered by visible region irradiation. ${ }^{9}$ Nevertheless, in the solid state devices, the covalent connection between metal electrodes and DTE molecules may cause just one-way switching from closed to open state, due to the strong electronic coupling formed in such a configuration in MTJs, ${ }^{10}$ thus affecting molecular functionality in photochromic isomerization.

In order to solve this problem, we designed and synthesized a novel and longer photochromic molecule, compound $\mathbf{1}$, by covalently 25 bonding two ruthenium fragments [HS- $\left.\mathrm{C}_{6} \mathrm{H}_{4}-\mathrm{C} \equiv \mathrm{C}(\mathrm{dppe})_{2} \mathrm{Ru}\right]^{+}$(dppe=1,2-bis(diphenylphosphino)ethane) on either ends of a DTE unit. The ruthenium complexes are expected to achieve an efficient coupling along the entire conjugated path, ${ }^{11}$ while decreasing the strong electronic coupling between the gold electrodes and the DTE groups observed with direct connections. Besides, such fragments are known to maintain the photoisomerization properties of DTEs, characterized by two open $(\boldsymbol{o})$ and closed (c) states, in order to ensure electronic switching between the $\pi$-conjugated and non-conjugated states. ${ }^{12}$ In addition, their intrinsic low oxidation potential close to 30 the Fermi level of gold should favour highest occupied molecular orbital (HOMO) mediated-tunneling. ${ }^{13}$

On-wire lithography (OWL), ${ }^{14}$ a chemistry-based nanofabrication technique, is a high-throughput method used to prepare nanogaps, affording precise control of the gap feature sizes down to $1 \mathrm{~nm}$. This method relies on the electrochemical deposition of multi-segmented metal nanowires within anodized aluminium oxide membranes and selective chemical etching of a sacrificial metal layer, which determines the gap size. The obtained nanogap structures have been proven to ensure effective electrical connection to target 35 molecules ${ }^{15,16}$ and to provide a promising potential platform to fabricate functional MTJs, such as rectifiers and memristors. ${ }^{6,17}$

In this contribution, we combine the advantages of photo-isomerization of DTE molecules and MTJs fabrication based on OWLproduced nanogaps to explore a photo-controllable reversible switching nanodevice with two-state conductance. Importantly, we found that the organometallic strategy with the DTE molecule 1 leads to a proper modulation of the strong electronic coupling between the gold electrodes and the DTE groups, solving the problem of one-way switching from closed to open state, ${ }^{10}$ without the use of gold

40 nanoparticles for example. ${ }^{18}$ In addition, theoretical calculations were performed in order to assess the geometries of both closed and open forms of 1 and understand the geometric reorganization upon irradiation, as well as the transmittance process through the molecule when incorporated between gold electrodes.

\section{Results and discussion}

The targeted binuclear compound 1 was readily obtained from the reaction between the diethynyl-substituted dithienylethene and the 45 vinylidene complex $\left[\mathrm{Cl}(\mathrm{dppe})_{2} \mathrm{Ru}=\mathrm{C}=\mathrm{CH}-p-\mathrm{C}_{6} \mathrm{H}_{4}-\mathrm{SAc}\right](\mathrm{OTf})$ in the presence of a base and of a non-coordinating salt, as previously described for analogous complexes (Figure 1a). ${ }^{19}$ The vinylidene precursor was obtained beforehand by the coordination of the alkyne AcS- $p-\mathrm{C}_{6} \mathrm{H}_{4}-\mathrm{C} \equiv \mathrm{CH}$ to the 16 -electron complex $\left[\mathrm{Cl}(\mathrm{dppe}){ }_{2} \mathrm{Ru}\right](\mathrm{OTf})$. Both complexes were fully characterized (ESI $\dagger$ ) and 1 shows very similar characteristics to those of the previously reported analogue complex, $\left[\mathrm{Cl}-(\mathrm{dppe}){ }_{2} \mathrm{Ru}-\mathrm{C} \equiv \mathrm{C}-\left(\mathrm{C}_{15} \mathrm{~S}_{2} \mathrm{~F}_{6} \mathrm{H}_{6}\right)-\mathrm{C} \equiv \mathrm{C}-\mathrm{Ru}(\mathrm{dppe})_{2}-\mathrm{Cl}\right] .{ }^{12}$ 


\section{a}
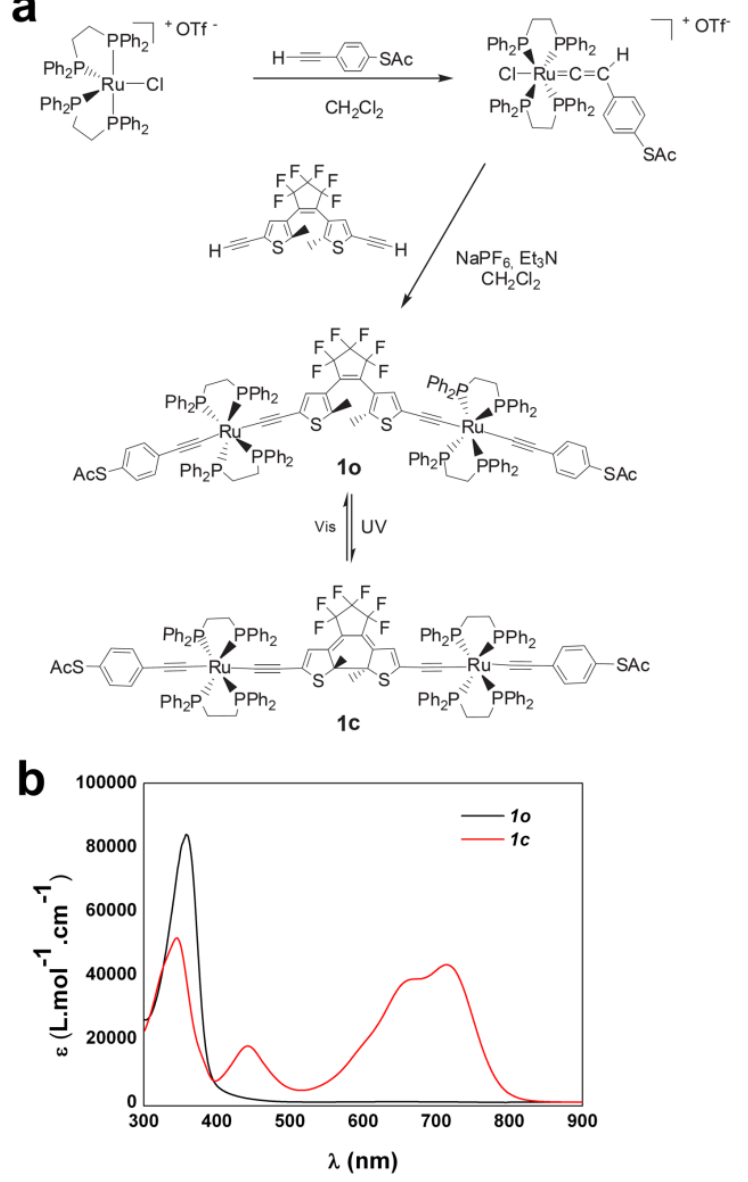

Fig. 1 (a) Scheme of synthesis of the molecular switch $\mathbf{1}$; (b) UV-Vis absorption spectra of $1 \boldsymbol{l o}$ and $\boldsymbol{l} \boldsymbol{c}$ in toluene.

It is to be noted that dithienylethenes can adopt two conformations, with the two thiophene rings in mirror symmetry (parallel conformation) and in the pseudo- $\mathrm{C}_{2}$ symmetry (anti-parallel conformation), and that the photocyclization reaction can only proceed from 5 the anti-parallel conformation. Importantly, as expected on the basis of ${ }^{1} \mathrm{H}$ and ${ }^{31} \mathrm{P}$ NMR characterizations and previously demonstrated by theoretical calculations for the analogue complex, ${ }^{12}$ only the antiparallel isomer is formed due to steric hindrance. Therefore, as highlighted in Figure 1b, isomerization studies in toluene unambiguously show that the photochromic conversion process upon irradiation of $1 o$ to the very stable $1 c$ complex is fully reversible in $\mathrm{UV}$-vis cells $\left([\mathrm{c}] \approx 10^{-5} \mathrm{~mol} \cdot \mathrm{L}^{-1}\right)$. More specifically, the colourless complex 10 displays an absorption at $\lambda_{\max }=359 \mathrm{~nm}\left(\varepsilon=84000 \mathrm{~L} \cdot \mathrm{mol}^{-1} \cdot \mathrm{cm}^{-1}\right)$. The transition associated with this excitation occurs 10 between the HOMO, $\pi$ (DTE) and $\pi / \mathrm{d}$ [AcS- $p-\mathrm{C}_{6} \mathrm{H}_{4}-\mathrm{C}_{2}-\mathrm{Ru}-\mathrm{C}_{2}$ ] in character, and the lowest unoccupied molecular orbital (LUMO) which is the corresponding $\pi^{*}$ of the DTE, where the LUMO, in particular, possesses two lobes on the methylated carbon atoms that can overlap upon rotation to lead to a ring closure (see below). ${ }^{12}$ Upon irradiation with UV light $(\sim 350 \mathrm{~nm})$, this band vanishes, while a broad absorption assigned to the deep green closed isomer $1 c$ appears at $\lambda_{\max }=713 \mathrm{~nm}\left(\varepsilon=45000 \mathrm{~L} \cdot \mathrm{mol}^{-1} \cdot \mathrm{cm}^{-1}\right)$. This absorption corresponds mainly to a HOMO $\left(\mathrm{Ru}_{\mathrm{d} / \pi^{-}}-\mathrm{C}_{2} \mathrm{DTE} \mathrm{E}_{\pi}\right) \rightarrow$ LUMO $\left(\mathrm{Ru}_{\mathrm{d} / \pi^{-}}-\mathrm{C}_{2} \mathrm{DTE} \pi_{\pi^{*}}\right)$ transition which removes bonding electrons between the 15 two methylated carbon atoms. It was previously shown that the broadness of the band is due the overlapping absorptions of different rotamers of $\boldsymbol{I c}$ in solution with various orientations of the metallic units with respect to the DTE plane. ${ }^{12}$ This $\mathbf{1} \boldsymbol{c}$-containing solution can be further bleached back to a colourless solution of 10 under visible light $(\sim 700 \mathrm{~nm})$ via ring opening, with quantitative recovering of the initial spectra. Complete conversions in both directions were confirmed with ${ }^{31} \mathrm{P}$ and ${ }^{1} \mathrm{H}$ NMR studies, with characteristic resonance shifts of the eight equivalent phosphorus atoms, and of the thiophene and methyl group protons (ESI $\dagger$ ). 
a

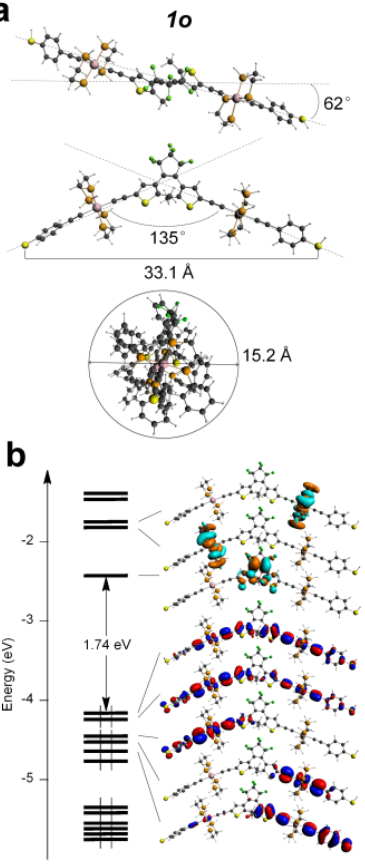

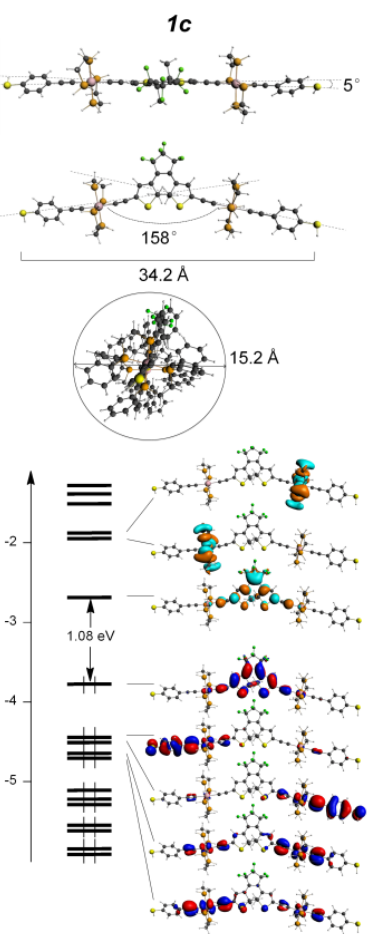

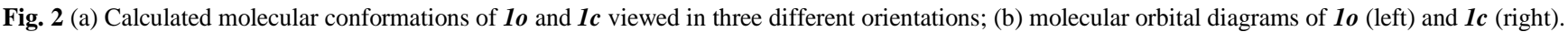
The contour values used for the MO representation are $\pm 0.03(\mathrm{e} / \mathrm{borh})^{1 / 2}$.

Then, in order to better predict the behaviour of the device, theoretical studies of molecular conformations and electronic structures 5 were performed (computational details, ESI†). The geometry optimization of simplified structures $\uparrow$ of $\boldsymbol{l o}$ and $\boldsymbol{l} \boldsymbol{c}$ in vacuum reveal different three-dimensional geometrical arrangements (Figure 2a), due to the modification of the DTE structure. ${ }^{20}$ The 10 skeleton presents an angle of roughly $135^{\circ}$ between the two acetylide branches (projected straight lines) with a distance of $33.1 \AA$ between the terminal sulfur atoms. The $\boldsymbol{l} \boldsymbol{c}$ conformation is slightly more spread out with a distance of $34.2 \AA$ between the two anchor atoms and an angle of $158^{\circ}$ between the two conjugated chains. Considering the S-S axis as reference, the two molecules can be included in cylinders 10 of same circumference $(c a .15 .2 \AA)$. When comparing the change in geometry between $\boldsymbol{l c}$ and $\boldsymbol{l o}$, a shortening of $1 \AA$ of the sulfursulfur distance is observed in 1o. It is attributed to a change in direction of the acetylide chain axis which is almost collinear in the closed form. The adaptability of $\mathbf{1 o}$ is remarkable since a constraint of only $0.03 \mathrm{eV}$ is needed to keep the same molecular length as that of $\boldsymbol{l} \boldsymbol{c}$ (S-S distance of $34.2 \AA$ ). This suggests that the structural changes between $\boldsymbol{l} \boldsymbol{c}$ and $\boldsymbol{l o}$ within nanogaps can occur without detachment of the molecule from the electrode.

15 The electronic structures of the simplified $\boldsymbol{l o}$ and $\boldsymbol{l} \boldsymbol{c}$ adducts are given in Figure $2 \mathrm{~b}$. The closed form $\boldsymbol{l c}$ is less stable than $\boldsymbol{l o}$ by 0.26 $\mathrm{eV}$. The electronic structure of $\boldsymbol{l} \boldsymbol{c}$ (that has one more double bond than $\mathbf{1 o}$ ) displays an additional MO in the HOMO-LUMO gap (i.e., the new HOMO) which has bonding character between the two carbon atoms of the newly formed bond. Important for conduction, this orbital is also delocalized over the conjugated carbon skeleton, including the ruthenium centres. From the above calculated results of both molecular conformations and electronic structures, it is shown that the conformational isomerization between $\mathbf{l o}$ and $\boldsymbol{l c}$ can be 20 achieved even when covalently immobilized within the nanogaps. Meanwhile, the different molecular orbital arrangement of $\boldsymbol{I} \boldsymbol{c}$ and $\boldsymbol{I o}$ anticipates a conductive switching of $\boldsymbol{I}$-based MTJs, suggesting that such a DTE molecule would be a promising candidate for fabrication of photo-modulable MTJs.

Experimentally, $\sim 5 \mu \mathrm{m}$ Au wire structures with $\sim 3 \mathrm{~nm}$ gaps, (which are consistent with the length of $\boldsymbol{I}$ ) were synthesized and cast onto a silicon substrate (containing a $600 \mathrm{~nm} \mathrm{SiO}_{2}$ layer) with patterned gold microelectrodes. Then, the wires were connected to the 25 microelectrodes by e-beam lithography and subsequent thermal deposition of chromium and gold. Scanning electron microscopy (SEM) revealed that the two ends of an Au nanowire were connected to two separate microelectrodes (Figure 3a), with the gap on the wire around $3 \mathrm{~nm}$ (Figure $3 \mathrm{~b}$ ) as expected. The unmodified nanogap device was immersed in a $5 \mathrm{ml}$ tetrahydrofuran (THF) solution of dithiol terminated $\boldsymbol{l c}$ (after deprotection of thiol, by eliminating the acetyl group with $5 \mu \mathrm{L}$ of $28 \%$ ammonia) for $24 \mathrm{~h}$. Through the formation of $\mathrm{Au}-\mathrm{S}$ bonds between the two sides of the nanogap and $\mathbf{l c}$, the molecules can be immobilized into the nanogap, as is depicted in Figure 30 $3 \mathrm{c}$. These covalent bonds will ensure a strong electronic coupling between $1 \boldsymbol{c}$ and the electrodes ${ }^{15,16}$ to achieve the photo-controllable conductance switching due to the photochromic properties of $\boldsymbol{l c}$ (Figure $3 \mathrm{~d}$ ). ${ }^{11}$

Two-terminal $I-V$ characterization of the $\sim 3 \mathrm{~nm}$ gap devices was conducted under a vacuum of $5 \times 10^{-5}$ Torr at room temperature in the dark both before and after $\mathbf{l c}$ assembly. The blank nanogap devices showed no conductance within the noise limit of the measurement $(<1 \mathrm{pA}$, Figure S4, ESI $\dagger$ ). However, when the $\sim 3 \mathrm{~nm}$ gap was loaded with a $\boldsymbol{l} \boldsymbol{c}$ monolayer, the devices exhibited an 35 obvious $I-V$ response (black curve in Figure $3 \mathrm{e})$ at low bias $(\leq 1 \mathrm{~V})$. The observed symmetry of the curves indicates that the $1 \boldsymbol{c}$ 
molecules were covalently bound to each of the gold electrodes on opposite sides of the gap. If the molecules were bound only to one contact, the I-V curves would display asymmetry due to different injection barriers. ${ }^{15}$ This $I-V$ characteristic explicitly suggests a successful fabrication of $\mathbf{1} \boldsymbol{c}$-based transport junctions. The yield for working devices is $22 \%$ ( 21 out of 94 devices with I > $1 \mathrm{nA}$ on a single chip with an area of $1 \mathrm{~cm} \times 1 \mathrm{~cm}$ ). In addition, it should be mentioned that the magnitude of the current under $1 \mathrm{~V}$ bias obtained ${ }_{5}$ from different $\mathbf{1 c}$-based devices varied in the range from $300 \mu \mathrm{A}$ to $10 \mathrm{nA}$ (Figure S5, ESI $\dagger$ ). This disparity is presumably mainly due to the different number of $\mathbf{1} \boldsymbol{c}$ molecules that are actually incorporated into the nanogap via chemical bonds with the gold surface at each side. The roughness and morphology of the gold surface, and the $\pm 0.2 \mathrm{~nm}$ gap size variation, may be among the reasons that cause these variations. $^{15}$

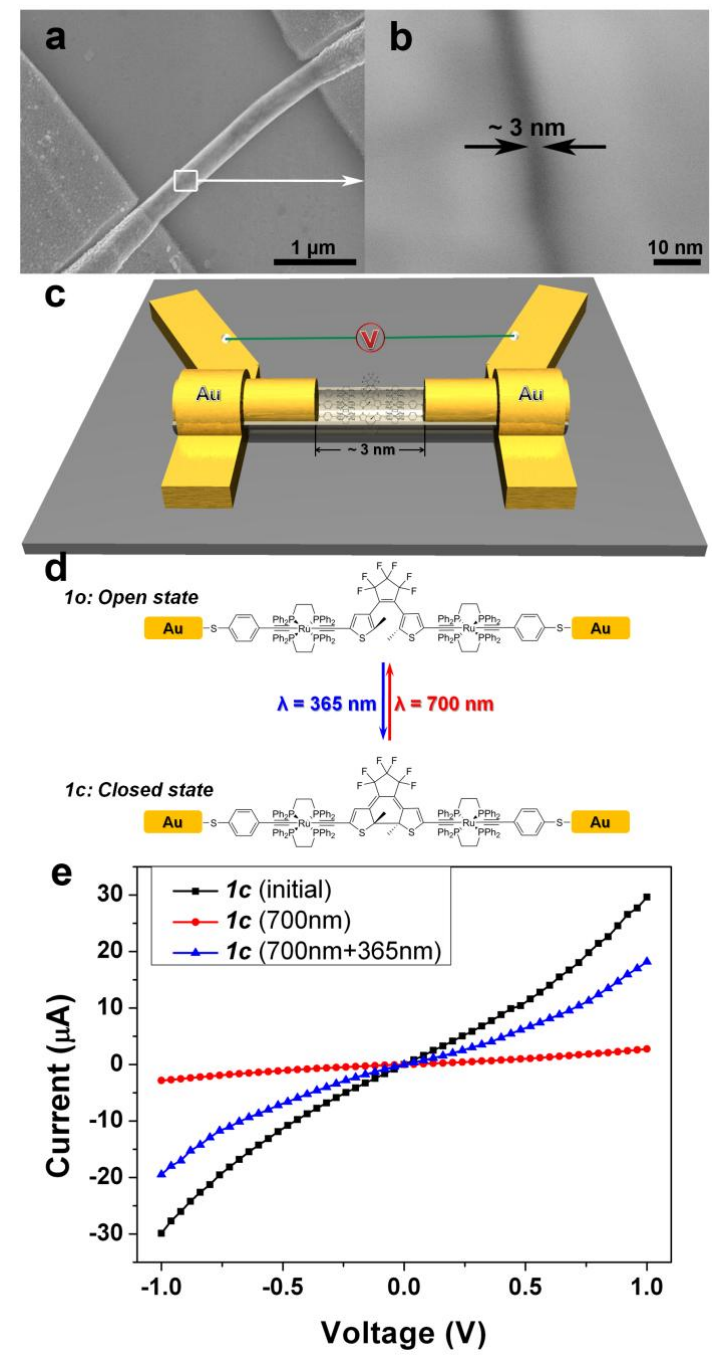

10 Fig. 3 (a) SEM image of a device fabricated with an OWL-generated nanowire; (b) SEM image of $~ 3 \mathrm{~nm}$ gap in the nanowire; (c) illustration of a prepared nanowire device with $\mathbf{I c}$ molecules spanning the $\sim 3 \mathrm{~nm}$ gap; (d) the scheme of isomerization of 1 covalently bonded into the nanogap under light at 365 $\mathrm{nm}$ and $700 \mathrm{~nm}$ light; (e) Representative $I-V$ characteristics of $\sim 3 \mathrm{~nm}$ OWL-generated gap devices loaded with $1 c$ molecules, as measured in the dark under vacuum (black curve: initial device; red curve: device after $700 \mathrm{~nm}$ irradiation for $2.5 \mathrm{~h}$; blue curve: device after subsequent $365 \mathrm{~nm}$ irradiation for $30 \mathrm{~min})$;

15 More interestingly, the I-V curves of $\mathbf{1} \boldsymbol{c}$-functionalized nanogap devices exhibited light-triggered switching. (Figure 3e and Figure S5, ESI $\dagger$ ) After the device was irradiated with visible light at a wavelength of $700 \mathrm{~nm}$ for $150 \mathrm{~min}$, the current decreased by about an order of magnitude, as shown in Figure $3 \mathrm{e}$ (red curve), thus indicating that the device is switched from high conductance (ON state) to low conductance (OFF state). Light at $365 \mathrm{~nm}$ was then employed to irradiate the device for $30 \mathrm{~min}$. It can be observed that the current surged back (blue curve in Figure 3e), suggesting the reverse switching of the device to the low-resistive ON state. Though the 20 conductivity of the device after switching was a somewhat lower than in the initial state, the $\mathbf{1 c}$-based devices have a high potential as light-triggered switches under different excitations. This bi-directional transformation is consistent with the photochromic properties of molecule 1 in solution. Note that the temperature-dependent I-V measurement was also performed in a large temperature range (20K300K) (Figure S6, ESI $\dagger$ ) and just less than twofold variation was observed, eliminating the influence of thermal effects on the device conductivity, and confirming the stability of the high conductance state in the dark (vide infra). Therefore, the photo-controllable ${ }_{25}$ structural rearrangement of $\boldsymbol{I}$ definitely affects the conductivity of the device, since the $\pi$-conjugation pattern in the closed form 
facilitates the electron transport along the molecule wire. ${ }^{15}$

It is worth noting that we also employed $\mathbf{1 o}$ to substitute $\mathbf{1} \boldsymbol{c}$ for device fabrications with same gap size and that these $\mathbf{1 o}$-based devices showed very low conductivity and no photochromic behaviour as $1 c$-based devices $(<10 \mathrm{pA}, 1 \mathrm{~V}$ bias, Figure S7, ESI $\dagger)$, suggesting that the MTJs cannot be achieved with 10 molecules. The failure could be ascribed to the conformation of 10 , as discussed in the theoretical 5 studies, which is less linear and rigid than $\mathbf{1 c}$, and hence less favourable to form a connection on the two opposite nanoelectrodes. Although these mono-grafted 10 molecules may experience the photo-isomerization under UV light, we still cannot measure the conductivity change of the devices that is dominated by the disconnection at one side of nanogap. Note that, based on the calculated 10 conformation, double bonding onto the same side of the gap could be proposed but the steric hindrance due to the phenyl groups would disfavour it (Figure S8, ESI $\dagger$ ) if molecules lie down on the surface. In addition, for 10 molecules connected to both nanoelectrodes, there 10 is no energy level suitable to support high conductivity of the device (see theoretical calculations).

Furthermore, in order to analyse these experimental current characteristics of the devices, we have calculated the transmission spectra of both the closed and open structures (as obtained in the gas-phase geometry with the constraint of matching the interelectrode gap size) when incorporating them in a gold nanojunction. Current flowing through the junction is obtained by integration of this spectrum in the bias transmission window, according to the Landauer formula. ${ }^{20,21}$ Transmissions at both equilibrium (zero bias) and under a bias of 0.6 ${ }_{15} \mathrm{~V}$ were calculated in order to take into account the polarization effects arising from the electric field. ${ }^{22}$ Transmissions for each isomer are separately reported in Figure 4a. The closed isomer $1 \boldsymbol{c}$ spectrum exhibits an intense peak of transmission near the Fermi level thus allowing for high conductivity. The applied bias induces a shift of this peak, keeping it at the limit of the transmission window and hence restricting the possibility of this isomer to theoretically achieve high conductivity. ${ }^{23}$ On the other hand, the open isomer 10 exhibits a small peak collapsing under bias. The theoretical closed/open current ratio at $0.6 \mathrm{~V}$ is around 40 which is consistent with the 20 one order of magnitude observed experimentally (Figure 3e), taking into account the high number of molecules in experimental nanojunctions as against our single-molecule calculations. By computing the molecular projected self-consistent Hamiltonian (MPSH) spectrum, we can associate each transmission peak of the spectra with a molecular state. ${ }^{21,22}$ Formally, the MPSH states can be described as an electronic reorganization of the isolated isomers upon substitution of the terminal hydrogen atoms by the gold electrodes. Relevant MPSH states are reported in Fig 4b. In comparison to the gas-phase calculations, we clearly identify the HOMO as the orbital aligned 25 near the Fermi level for both isomers.

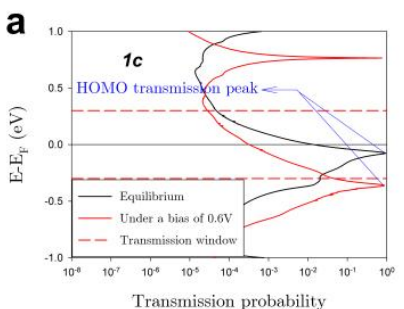

b

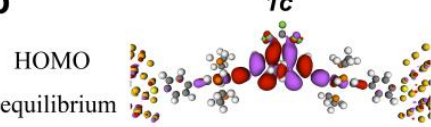

$\mathrm{E}-\mathrm{EF}=-0.08 \mathrm{eV}$

HOMO

$0.6 \mathrm{~V}$ bias

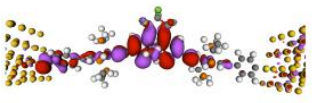

$\mathrm{E}-\mathrm{EF}=-0.23 \mathrm{eV}$

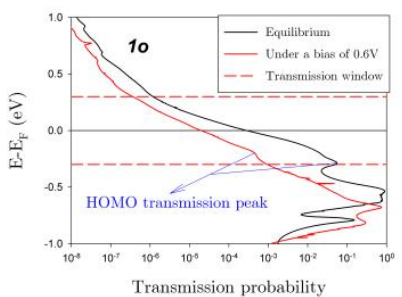

10

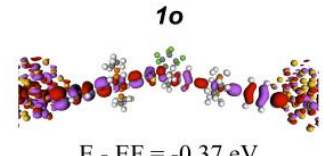

$\mathrm{E}-\mathrm{EF}=-0.37 \mathrm{eV}$

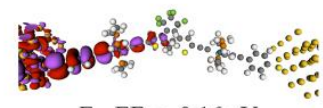

$\mathrm{E}-\mathrm{EF}=-0.16 \mathrm{eV}$

Fig. 4 (a) Transmission spectra (in log scale) of the closed and open isomers around the Fermi level of the electrodes which are set to zero for convenience. The black line corresponds to the calculation at equilibrium and the red line in non-equilibrium to observe the bias effect. The red dashed line delimits the transmission window at $0 \mathrm{~K}$ showing the part of the transmission spectra which must be integrated to obtain the current at $0.6 \mathrm{~V}$. The HOMO transmission 30 peaks discussed in the text are highlighted in blue; (b) MPSH state identified as the HOMO orbital for the closed and open isomers. The first row corresponds to the calculations at equilibrium and the second to the non-equilibrium calculations showing the polarization effects.

The intense peak observed for the closed isomer $1 \boldsymbol{c}$ is driven by the good delocalization of the MPSH HOMO on the entire photochromic core between the ruthenium linkers, which are crucial to ensure a smooth transmission pathway. However, this orbital shows a moderate weight on the linkers and the gold surface, leading to a valuable reduction of hybridization with the metal, which helps

35 to avoid the quenching of the photochromic switch ${ }^{24}$ in order to maintain photoreversibility. Thus, it is the ruthenium moieties that judiciously adjust the electronic coupling between the photochromic part and the metal electrodes. Under bias, the photochromic part remains unchanged while a polarization of the linker towards the positive side takes place. The final shape rationalizes the conserved intensity of the peak under bias and points to its pinning to the lower (positive) Fermi level. In contrast, the HOMO of the open isomer 10 in the junction has a small weight on the central photochromic part; this breaks the delocalization and gives rise to a weak 40 transmission peak near the Fermi level. Under bias, the orbital is completely changed and gets strongly polarized leading to the collapse of the weak transmission peak. 
Finally, we have demonstrated that such a $\mathbf{l c}$-functionalized nanodevice can be used as a photo-modulable switch, for which reversibility, repeatability, and stability upon irradiation during ON/OFF cycles are all key characteristics. The ON/OFF cycle test conducted under $1 \mathrm{~V}$ bias is shown in Figure 5a. The repeatable wave-shape current response is generated by alternate irradiation of light with wavelengths at $700 \mathrm{~nm}$ and $365 \mathrm{~nm}$, reflecting the reversible conductive switching of the device between ON and OFF. It is clearly 5 observed that upon $700 \mathrm{~nm}$ irradiation, the conductance of the device gradually decreases following the isomerization from $\mathbf{1 c}$ to $\mathbf{1 o}$, while upon $365 \mathrm{~nm}$ irradiation, the conductance is progressively enhanced due to the recovery of the $1 c$ arrangement. The conductivity of nanodevice is dominated by the amount ratio between $1 \boldsymbol{c}$ and $\mathbf{l o}$ bridging the nanogap and therefore the dynamics of 1 isomerization can be studied through the conductance change of the devices. The switching dynamics can be reflected by the conductance change of nanodevices, as shown in Figure 5. The reaction rate of the UV-triggered isomerized process of 1 immobilized between two 10 nanoelectrodes is apparently higher than that of the visible light-triggered process and the ratio of the reaction constants (slopes of $\ln (\mathrm{G})$ vs time in Figure S9, ESI $\dagger$ ) $k_{365}$ to $k_{700}$ is about 3. Although, it is consistent with the behaviours of the parent complex ${ }^{12}$ and 1 (Figure $\mathrm{S} 10, \mathrm{ESI} \dagger$ ) in solution showing a much faster isomerization under UV irradiation than under visible light, the kinetics of molecular isomerization is uncomparable due to the distinctly different condition and microenvironment of the photochromic molecules in these two system, such as the medium (vacuum, organic solvent), molecular state (up to thousands of immobilized in a nanogap, $1 \mu \mathrm{M}$ free in 15 solution), and even the light path (penetration into a nanogap, direct irradiation). In addition, in order to test whether the conductive switching is really photo-related, we also measured the device in dark for $1 \mathrm{~h}$, and found no notable resistive change. The reversible light-triggered conductive switching can be repeatedly operated for several cycles, maintaining a stable bi-state of system.
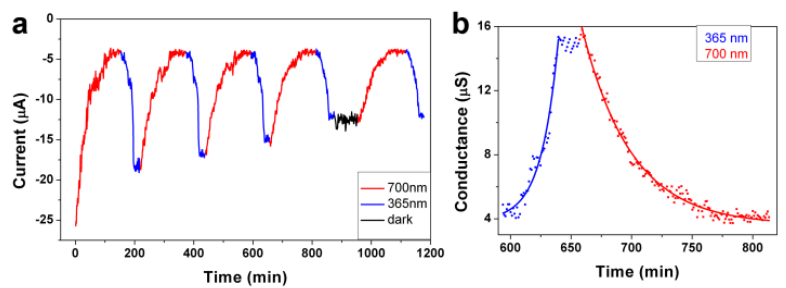

Fig. 5 (a) Current response of an $\mathbf{l c}$-based nanogap device at $-1 \mathrm{~V}$ under alternate irradiation of light at $700 \mathrm{~nm}$ and $365 \mathrm{~nm}$ for ON/OFF cycle test (the 20 black range represents the state of the device in the dark); (b) conductance (G) of an $\mathbf{1} \boldsymbol{c}$-based nanogap device under alternate irradiation of light at $365 \mathrm{~nm}$ (blue) and $700 \mathrm{~nm}$ (red) for one ON/OFF cycle.

Nevertheless, a progressive loss of reversibility is observed in the course of such a cycling experiment, as often observed. ${ }^{8}$ This can be the result of the stochastic behaviour of thiols on gold leading to the desorption of molecules from the substrates, ${ }^{25}$ that is increased by the slight additional constraint upon opening. One has also to consider the effect of UV irradiation, causing the decomposition of the 25 molecules, ${ }^{26}$ and the ductility of gold in the reorganization process occurring upon opening. ${ }^{27}$ The reorganizations that follow bond breaking with the surface or the gold wire pulling§ might be unfavourable for re-anchoring and/or for reclosure respectively. We could also observe that, in comparison to single-molecule studies on a related molecule, ${ }^{8 \mathrm{~b}}$ the irradiation time required to reach the photostationary state is longer. This is reasonable, since the nanogap can contain thousands of molecules, and the number of those isomerised is a function of exposure time. ${ }^{28}$ Finally, it is also worth noting that the observed closed/open ratio about one order of 30 magnitude is consistent with the theoretical calculation of not only molecule $\mathbf{1}$ in gold nanogap here, but also relative molecules in previous reports, ${ }^{29}$ which is also comparable with conductance change observed in single-molecule switches on other DTE molecules. ${ }^{8 c, 8 e, 30}$

\section{Conclusions}

In summary, we have demonstrated a photo-controllable MTJ nanodevice based on the association of a ruthenium-based organometallic 35 molecular wire including a DTE unit and an OWL-generated nanogap. The obtained devices perform bi-directional conductive switching upon irradiation with UV and visible light. The theoretical calculations performed on 1 reveal (i) that the ruthenium acetylide moieties decrease judiciously the electronic coupling of the DTE fragment with the metal electrodes in its open form, allowing the system to close upon irradiation, and (ii) that the delocalization of the HOMO of the closed isomer lying near the Fermi level of the junction is high enough to lead to a good conductivity. The switching in conductivity is explained by a weak delocalization in the

40 photochromic part in addition to the polarization of the HOMO level of the open form lying near the Fermi level. Therefore, such a photo-controllable device not only shows a potential application in functional nanocircuits, but also provides a promising platform to clarify the nature of charge transport across single molecules.

\section{Acknowledgements}

${ }_{45}$ The authors thank the support from the Singapore Ministry of Education Tier2 (MOE2010-T2-1-017), Merlion program, Université de Rennes 1, the CNRS, the ANR (ANR-09-JCJC-0025), PHC Tournesol FR 2012. This work was performed using HPC resources from GENCI-CINES and GENCI-IDRIS (Grant 2010-80649). C.V.D. and J.C. are FNRS research fellows. 


\section{Notes and references}

${ }^{a}$ School of Materials Science and Engineering, Nanyang Technological University, 50 Nanyang Avenue, Singapore 639798, Singapore. E-mail: chenxd@ntu.edu.sg; Web: http://www.ntu.edu.sg/home/chenxd/

${ }^{b}$ Institut des Sciences chimiques de Rennes, UMR 6226 CNRS - University de Rennes 1, F-35250, Rennes, France. E-mail: Stephane.rigaut @ univ5 rennes1.fr

${ }^{c}$ Laboratory for Chemistry of Novel Materials, University of Mons, Place du Parc, 20, 7000 Mons, Belgium.

$\dagger$ Electronic Supplementary Information (ESI) available: Experimental processes of 1 synthesis, and nanodevice fabrication and measurement; Computational Details; Experimental $I-V$ curves of blank device, different $\boldsymbol{l} \boldsymbol{c}$-based devices, and $\mathbf{l o}$-based device; Geometries of 10 arrangements. See DOI: $10.1039 / \mathrm{b} 000000 \mathrm{x} /$

$10 \ddagger$ Phenyl groups of the dppe were replaced by hydrogen atoms to reduce computational cost

$\S$ Gold wire pulling also modifies the conductivity.

1 a) A. Nitzan, M. A. Ratner, Science, 2003, 300, 1384; b) N. J. Tao, Nat. Nanotechnol., 2006, 1, 173; c) S. M. Lindsay, M. A. Ratner, Adv. Mater., $2007,19,23$.

152 a) C. Joachim, J. K. Gimzewski, A. Aviram, Nature, 2000, 408, 541; b) B. A. Mantooth, P. S. Weiss, Proc. IEEE, 2003, 91, 1785; c) J. M. Tour, M. Kozaki, J. M. Seminario, J. Am. Chem. Soc., 1998, 120, 8486; d) J. M. Tour, Acc. Chem. Res., 2000, 33, 791.

3 A. Aviram, M. A. Ratner, Chem. Phys. Lett., 1974, 29, 277.

4 S. J. Tans, A. R. M. Verschueren, C. Dekker, Nature, 1998, 393, 49.

5 A. R. Pease, J. O. Jeppesen, J. F. Stoddart, Y. Luo, C. P. Collier, J. R. Heath, Acc. Chem. Res., 2001, 34, 433.

206 F. Meng, L. Jiang, K. Zheng, C. F. Goh, S. Lim, H. H. Hng, J. Ma, F. Boey, X. Chen, Small, 2011, 7, 2957.

7 a) C. S. Tsai, J. K. Wang, R. T. Skodje, J. C. Lin, J. Am. Chem. Soc., 2005, 127, 10788; b) M. J. Comstock, N. Levy, A. Kirakosian, J. W. Cho, F. Lauterwasser, J. H. Harvey, D. A. Strubbe, J. M. J. Frechet, D. Trauner, S. G. Louie, M. F. Crommie, Phys. Rev. Lett., 2007, 99, 038301; c) M. Del Valle, R. Gutierrez, C. Tejedor, G. Cuniberti, Nat. Nanotechnol., 2007, 2, 176.

8 a) A. J. Kronemeijer, H. B. Akkerman, T. Kudernac, B. J. van Wees, B. L. Feringa, P. W. M. Blom, B. de Boer, Adv. Mater., 2008, 20, 1467; b) N.

25 Katsonis, T. Kudernac, M. Walko, S. J. van der Molen, B. J. van Wees, B. L. Feringa, Adv. Mater., 2006, 18, 1397; c) K. Uchida, Y. Yamanoi, T. Yonezawa, H. Nishihara J. Am. Chem. Soc., 2011, 133, 9239; d) T. Kudernac, N. Katsonis, W. R. Browne, B. L. Feringa, J. Mater. Chem., 2009, 19, 7168; e) E. S. Tam, J. J. Parks, W. W. Shum, Y.-W. Zhong, M.B. Santiago-Berríos, X. Zhang, W. Yang, G. K.-L. Chan, H. D. Abruña, D. C. Ralph, ACS Nano, 2011, 5, 5115; f) S. V. Aradhya, J. S. Meisner, M. Krikorian, S. Ahn, R. Parameswaran, M. L. Steigerwald, C. Nuckolls, L. Venkataraman, Nano Lett., 2012, 12, 1643.

309 a) M. Irie, Chem. Rev., 2000, 100, 1685; b) J. Areephong, W. R. Browne, N. Katsonis, B. L. Feringa, Chem. Commun., 2006, 3930; c) V. Guerchais, L. Ordronneau, H. Le Bozec, Coord. Chem. Rev., 2010, 254, 2533; d) I. Yildiz, E. Deniz, F. M. Raymo, Chem. Soc. Rev., 2009, 38, 1859; e) H. Tian and S. Wang, Chem. Commun., 2007, 781.

10 a) D. Dulic, S. J. van der Molen, T. Kudernac, H. T. Jonkman, J. J. D. de Jong, T. N. Bowden, J. van Esch, B. L. Feringa, B. J. van Wees, Phys. Rev. Lett., 2003, 91, 207402; b) S. J. van der Molen, H. van der Vegte, T. Kudernac, I. Amin, B. L. Feringa, B. J. van Wees, Nanotechnology, 2006, 17, 310.

11 a) S. Rigaut, C. Olivier, K. Costuas, S. Choua, O. Fadhel, J. Massue, P. Turek, J. Y. Saillard, P. H. Dixneuf, D. Touchard, J. Am. Chem. Soc., 2006, 128, 5859; b) K. Costuas, S. Rigaut, Dalton Trans., 2011, 40, 5643; c) C. Olivier, K. Costuas, S. Choua, V. Maurel, P. Turek, J.-Y. Saillard, D. Touchard ,S. Rigaut J. Am. Chem. Soc., 2010, 132, 5638; d) E. Di Piazza., L. Norel, K. Costuas, A. Bourdolle, O. Maury, S. Rigaut, J. Am. Chem. Soc., 2011, 133, 6174; e) E. Wuttke, F. Pevny, Y.-M. Hervault, L. Norel, M. Drescher, R. F. Winter, S. Rigaut Inorg. Chem. $2012,51,1902$.

4012 Y. Liu, C. Lagrost, K. Costuas, N. Tchouar, H. Le Bozec, S. Rigaut, Chem. Commun., 2008, 6117.

13 a) B. S. Kim, J. M. Beebe, C. Olivier, S. Rigaut, D. Touchard, J. G. Kushmerick, X.-Y. Zhu, C. D. Frisbie, J. Phys. Chem. C, 2007, 111, 7521; b) L. Luo, A. Benameur, P. Brignou, S. H. Choi, S. Rigaut, C. D. Frisbie, J. Phys. Chem. C, 2011, 115, 19955

14 a) L. Qin, S. Park, L. Huang, C. A. Mirkin, Science, 2005, 309, 113; b) S. J. Hurst, E. K. Payne, L. Qin, C. A. Mirkin, Angew. Chem. Int. Ed., 2006, 45, 2672.

4515 X. Chen, Y. M. Jeon, J. W. Jang, L. Qin, F. Huo, W. Wei, C. A. Mirkin, J. Am. Chem. Soc., 2008, 130, 8166.

16 X. Chen, A. B. Braunschweig, M. J. Wiester, S. Yeganeh, M. A. Ratner, C. A. Mirkin, Angew. Chem. Int. Ed., 2009, 48, 5178.

17 X. Chen, S. Yeganeh, L. Qin, S. Li, C. Xue, A. B. Braunschweig, G. C. Schatz, M. A. Ratner, C. A. Mirkin, Nano Lett., $2009,9,3974$.

18 a) S. J. van der Molen, J. H. Liao, T. Kudernac, J. S. Agustsson, L. Bernard, M. Calame, B. J. van Wees, B. L. Feringa, C. Schonenberger, Nano Lett., 2009, 9, 76; b) G. D. Lilly , A. C. Whalley, S. Grunder , C. Valente, M. T. Frederick, J. F. Stoddart, E. A. Weiss, J. Mater. Chem., 2011, 21, 11492;

50 c) M. Ikeda, N. Tanifuji, H. Yamaguchi, M. Irie, K. Matsuda, Chem. Commun., 2007, 1355.

19 a) C. Olivier, B.-S. Kim, D. Touchard, S. Rigaut, Organometallics, 2008, 27, 509; b) A. Benameur, P. Brignou, E. Di Piazza, Y.-M. Hervault, L. Norel, S. Rigaut, New. J. Chem., 2011, 35, 2105.

20 Y. Imry, R. Landauer, Rev. Mod. Phys., 1999, 71, S306.

21 M. Brandbyge, J.-L. Mozos, P. Ordejon, J. Taylor, K. Stokbro, Phys. Rev. B, 2002, 65, 165401.

5522 J. Taylor, H. Guo, J. Wang, Phys. Rev. B, 2001, 63, 245407.

23 A. Odell, A. Delin, B. Johansson, I. Rungger, S. Sanvito, ACS Nano, 2010, 4, 2635.

24 M. Zhuang, M. Ernzerhof, J. Chem. Phys. 2009, 130, 114704.

25 a) G. K. Ramachandran, T. J. Hopson, A. M. Rawlett, L. A. Nagahara, A. Primak, S. M. Lindsay, Science, 2003, 300, 1413; b) C. Vericat, M. E. Vela, G. Benitez, P. Carro, R. C. Salvarezza, Chem. Soc. Rev., 2010, 39, 1805.

6026 M. Lewis, M. Tarlov, K. Carron, J. Am. Chem. Soc., 1995, 117, 9574.

27 a) D. Krüger, H. Fuchs, R. Rousseau, D. Marx, M. Parrinello, Phys. Rev. Lett., 2002, 89, 186402; b) L. Romaner, G. Heimel, M. Gruber, J.-L. Brédas, E. Zojer, Small, 2006, 2, 1468; c) R. J. C. Bastista, P. Ordejón, H. Chacham, E. Artecho, Phys. Rev. B, 2007, 75, 041402.

28 A. S. Kumar, T. Ye, T. Takami, B. -C. Yu, A. K. Flatt, J. M. Tour, P. S. Weiss, Nano Lett., 2008, 8, 1644.

29 a) J. Li, G. Speyer, O. F. Sankey, Phys. Rev. Lett., 2004, 93, 248302; b) Y. Tsuji, A. Staykov, K. Yoshizawa, J. Phys. Chem. C, 2009, 113, 21477; c) J. Huang, Q. Li, H. Ren, H. Su, Q. W. Shi, J. Yang, J. Chem. Phys., 2007, 127, 094705.

30 a) J. He, F. Chen, P. A. Liddell, J. Andréasson, S. D. Straight, D. Gust, T. A. Moore, A. L. Moore, J. Li, O. F. Sankey, S. M. Lindsay, Nanotechnology, 2005, 16, 695; b) A. C. Whalley, M. L. Steigerwald, X. Guo, and C. Nuckolls, J. Am. Chem. Soc., 2007, $129,12590$. 